\title{
Música reggae y modulaciones sociales: notas acerca de la relación individuo-grupo en una isla caribeña*
}

\author{
Rafael Andrés Sánchez Aguirre**
}

\section{Resumen}

Recibido: 7 de marzo de 2015

Evaluado: 23 de abril de 2015

Aceptado: 7 de mayo de 2015
La relación individuo-grupo es un tema central en diversos ámbitos del conocimiento; asunto que también resulta relevante en el campo musical. En este escrito, se asume que la musicalidad individual está ligada estructuralmente —más no agotada- a una musicalidad social e histórica. De tal forma, se intenta sugerir algunas líneas de reflexión acerca de la práctica de la música reggae en una isla del Caribe. El análisis de este fenómeno musical permitirá reconocer dimensiones de colectividad que los músicos y miembros de la comunidad van tejiendo. Se ha realizado un ejercicio de carácter sociológico, etnográfico y de revisión histórica, para detallar discrepancias sonoras, síncopas sociales y resistencias culturales que fortalecen sentidos de acción colectiva.

Palabras clave: música reggae, San Andrés Isla, síncopa social, sociología de la emociones.

El presente escrito es resultado parcial del proyecto de investigación Sociología de las emociones y de la música. Regulación emocional, música e individualización, el caso de San Andrés Isla, financiado por el Consejo Nacional de Investigaciones Científicas y Técnicas (Conicet) (Argentina). Cómo citar este artículo: Sánchez Aguirre, R.A. (2015). Música reggae y modulaciones sociales: notas acerca de la relación individuo-grupo en una isla caribeña. Hallazgos, 12(24), 159-175 (doi: http://dx.doi.org/10.15332/s1794-3841.2015.0024.09).

** Doctor en Ciencias Sociales, Universidad de Buenos Aires (Argentina); becario postdoctoral Conicet, Universidad de Buenos Aires, Grupo de Estudios Sociológicos sobre Cuerpos/Emociones (Gesce). Investigador del Centro de Investigaciones y Estudios Sociológicos (CIES) (Argentina). Correo electrónico: rasaguirre@gmail.com 


\title{
Reggae music and social modulations: notes on the individual-group relation in a Caribbean island
}

\begin{abstract}
The relationship between individual and group is a central topic in different fields of knowledge. It is an important matter that constitutes the music too. This paper considers that personal-musicality is linked structurally -but not exhausted- to a socio historical musicality. Thus, it tries to suggest some lines of reflection about the practice of reggae music in a Caribbean island. The analysis of this musical phenomenon will allow us to recognize dimensions of collectivity that musicians and listeners are weaving. This work develops a sociological/ethnographical exercise and historical review to detail sonorous discrepancies, social syncopations and cultural resistances that strengthen collective action.
\end{abstract} Received: March 7, 2015 Evaluated: April 23, 2015 Accepted: May 7,2015

Keywords: Reggae music, San Andrés Island, social syncope, sociology of emotions. 


\section{Música reggae e modulações sociais: notas com respeito à relação individuo-grupo em uma ilha do caribe}

Recebido: 7 de março de 2015

Avaliado: 23 de abril de 2015 Aceito: 7 de maio de 2015

\section{Resumo}

A relação individuo-grupo é um tema central em diversos âmbitos do conhecimento; assunto que também é relevante no campo musical. Em este escrito, assume-se que a musicalidade individual está ligada estruturalmente -mas não esgotada- a uma musicalidade social e histórica. Dessa maneira, tenta-se sugerir algumas líneas de reflexão sobre a prática da música reggae em uma ilha do Caribe. A análise deste fenômeno musical permitirá reconhecer dimensões de coletividade que os músicos e membros da comunidade vão criando. Tem se realizado um exercício de caráter sociológico, etnográfico e de revisão histórica, para detalhar discrepâncias sonoras, síncopes sociais e resistências culturais que fortalecem sentidos de ação coletiva.

Palavras-chave: música reggae, San Andrés Ilha, síncope social, sociologia das emoções. 
Do you remember the days of slavery?

And how they beat us and how they worked us so hard

and they used us

'til they refuse us

Do you remember the days of slavery?

Burning Spear

The feel of the music is the feel of their common history, the burden of their history [...] You feel it because it is your pain; you feel it because it is your hunger,

it is your sprout.

Linton Kwesi Johnson

En este texto se busca detallar algunas reflexiones acerca de la manera como se da la definición de acciones individuales en el marco de pautas figuradas grupalmente. Este tema se abordará a partir de un ejercicio de carácter sociológico-histórico procesual y etnográfico —que incluye elementos de reconstrucción sociohistórica, de la experiencia práctica con un grupo de música reggae, de la vivencia de esta cultura musical en una isla del Caribe y la observación de otros grupos del mismo géneroEn la primera parte serán presentadas algunas inquietudes conceptuales sobre los equilibrios de relación entre individuos y colectivos, proponiendo un contrapunto con el campo musical. En la segunda parte, se aborda el contexto de la música reggae y los aspectos generales de su práctica. Finalmente, en la tercera parte, se ofrece una reflexión del caso de la isla de San Andrés (territorio de la República de Colombia) para problematizar el lugar de la música en la afirmación de modalidades de relaciones interpersonales.

Es necesario señalar que se hará referencia, en adelante, a los integrantes de la comunidad sanandresana como raizales, esto permitirá precisar que se estudia al grupo que ha habitado este territorio con mayor tiempo y que se ha autoafirmado como la población originaria. La definición propuesta en el Estatuto Raizal dice, "[p]ueblo raizal: etnia anglo africana tradicionalmente asentada en el archipiélago con lenguaje, cultura, historia y ancestro propio" (Restrepo y Ramírez, 2001, p. 51). El principal propósito consiste en analizar algunos elementos vivenciales relativos a los factores grupales que pesan en la afirmación de dinámicas musicales, como parte de un ejercicio sociológico sobre las sensibilidades (no se busca profundizar sobre el tema de las identidades o las representaciones colectivas en esta ocasión).

El ejercicio analítico-argumentativo de este escrito está sostenido a partir de la revisión de investigaciones históricas sobre la música y el Caribe (Rao y Sedlaczek, 2012; Benítez, 1997; Borde, 1973; Calvancanti, 1985; Houk, 1995), sociológicas sobre fenómenos emotivo-musicales (Simmel, 2003; Elias, 1991; Grosso, 2009; Magallanes et al., 2014), etnomusicológicas sobre los "sentidos sonoros grupales" (Carvalho, 1995; Feld, 1982; Madrid, 2008), e histórico-culturales sobre la isla de San Andrés (Bermúdez, 2003; Clemente, 1989; Parsons, 1985). Así mismo, las reflexiones se apoyan en las visitas que se realizaron a dicha isla entre 2004 y 2007 en medio de la finalización de una tesis de maestría en Historia (Sánchez, 2007) y de preparación de una tesis doctoral en ciencias 
sociales (ambas relativas a fenómenos culturales sanandresanos) (Sánchez, 2014).

En San Andrés se mantuvieron conversaciones con músicos raizales y se les acompañó en varias de sus presentaciones, la mayoría dirigidas a turistas y comerciantes y algunas pocas "exclusivas" de la comunidad (a las que me dieron el permiso de asistir). Los informantes centrales fueron cinco integrantes de la comunidad raizal, personajes representativos en su área profesional, tres de ellos músicos, una persona dedicada a la dirección teatral y una lingüista que acompañó nuestro ejercicio de análisis musical hasta el final. En el proceso se mantuvieron charlas informales con abuelos, profesores, pescadores, vendedores ambulantes, guías turísticos y empleados públicos, quienes ofrecieron sus voces y plantearon su posición sobre diversos temas. Varias de sus voces son presentadas a través de este escrito, pero por petición de la mayoría de estos participantes hemos omitido sus nombres verdaderos.

Ya que las dinámicas musicales en Jamaica son ricas y complejas, con numerosos desarrollos relacionados con la fuerza, peso, transformación y movimientos de la música reggae, optamos por referirnos a ellas en la medida que han sido apropiadas en San Andrés y releídas en la clave social local. Así, se aclara que nuestra experiencia en este contexto insular no pretende agotar el universo vivencial, ni interpretativo acerca de los procesos sociomusicales caribeños. Más bien, se intenta reconocer, a través de nuestra participación en una práctica musical, aquellos elementos estructurales que han permitido el mantenimiento de una sonoridad-emotividad disruptiva que jalona síncopas sociales en San Andrés y que pueden ser compatibles con dinámicas sociomusicales de otras islas de la región ${ }^{1}$.

\section{I}

Para hablar de la relación individuo-grupo es necesario reconocer que la construcción de la individualidad en la modernidad corresponde a un proceso histórico de configuraciones sociales en las que no ha habido un único sentido de "desenvolvimiento". Más bien ha primado un alto grado de incertidumbre respecto a las formas sociales que se gestaron a partir de acciones individuales que no tenían como plan propio fundar una "edad moderna". Esto quiere decir que no hubo una planificación del paso de una sociedad feudal hacia una sociedad burguesa dentro de un ejercicio racional previsto individualmente ni grupalmente. Tampoco hubo una planificación hecha por los músicos medievales para establecer una "música moderna" (Edström, 2012). Por el contrario, se fueron entretejiendo fuerzas, potencias sociales (sonoras) y culturales que permitieron una concordancia en aras de la creación de espacios de intercambio, de encuentro y de comercio, de la mano con la instalación de pequeños burgos que fueron la base para un nuevo orden de relaciones.

En el mismo sentido, las prácticas cotidianas fueron posibilitando la afirmación de una

1 La síncopa social es un recurso conceptual que proponemos para señalar que en los procesos históricos de diferentes grupos humanos se han ido configurando contratiempos, rupturas con las regularidades, ritmos sociales a destiempo que no siguen con absoluta obediencia las marcas promovidas desde el establecimiento. Se trata entonces de reconocer esas acciones de los colectivos humanos, que han sido silenciadas a través de la historia y que funcionan como potenciales fuentes para la comprensión y la reorientación de nuestras acciones en la actualidad. 
tendencia a la individualidad que no existía por ejemplo en el siglo XV y en siglos anteriores. A través de propuestas filosóficas como la de Descartes, se fue evidenciando una mayor fuerza, en términos reflexivos, en el camino de la afirmación de una idea del "yo" (Elias, 1990). Tal concepto, que no había sido referenciado hasta ese momento de forma tan detallada, es una huella de la concreción que se iba perfilando en ciertos espacios sociales y que con el tiempo fue asumido en general por toda la comunidad euro-occidental. Tan habituados nos encontramos actualmente a un sentido de individualidad, de yoidad, que a la mayoría de las personas les resulta complicado imaginar que ese yo personal no hizo parte de los humanos en otro tiempo histórico reciente.

De manera análoga, el lugar de la música y de los músicos en otras épocas fue diferente al de la actualidad, no siempre existieron las estrellas o grandes talentos haciendo giras monumentales ni siendo el único centro de atención. Hubo una serie de pasos en la historia que hoy podemos enlazar, que trascurren desde lo que fue la música occidental con relativo protagonismo en la vida de las personas, hacia la música como centro de anudamiento de percepciones y modelo de éxito - como don de algunos pocos "bienaventurados" - . Si vemos algunas pinturas de la Edad Media podremos encontrar la marginalidad del músico en la vida cotidiana, generalmente al borde de las dinámicas sociales y como un ambientador de las situaciones (De Vrij, 2006; Brueghel y Bianconi, 1988)2. En llamativo contraste, los tiempos recientes dejan ver casos en los que

2 Ver, por ejemplo, las siguientes pinturas: http://www. pieter-bruegel-the-elder.org/Peasant-Wedding,-c.-1568-large.html o http://www. bridgemanart.com/asset/550604/Burlesque-Feast-by-Jan-Mandyn. las personas van por la calle enchufadas a sus dispositivos personales de sonido, embelesadas por las canciones de sus artistas favoritos. Tal cambio de lugar de la música puede considerarse desde una perspectiva de construcción de la individualización, de la "privatización de las pasiones" (Elias, 1991; Scribano, 2012).

El lugar y el papel de la música han ido variando de acuerdo con cada sociedad y con su historia; podría hablarse de una especie de ritmo social en el que por momentos la música ha tenido una u otra condición. Lo que por ahora puede sostenerse es que el actual protagonismo de esta se encuentra ligado a un ejercicio de modelación de la sensibilidad, de lo pasional a partir de la construcción de grandes enunciados/ imágenes sonorizadas que son promovidas como ejemplos del comportamiento normal individual (piénsese, por ejemplo, en el papel que cumplen los éxitos musicales globales como referentes sentimentales). A la par, la expresión de lo pasional debe mantenerse en el ámbito de lo privado o dentro de los límites de lo "público-virtual" (redes sociales, reality shows), siendo la música uno de esos lugares socialmente legitimados para la representación de las pasiones (no es común ir por la calle diciendo a todo el mundo lo que sentimos — caso contrario en Facebook y que merecería un estudio particular-, pero sí es posible ir cantando, arrullando nuestros sentimientos, rememorando una canción y sus mensajes).

En la actualidad, el proceso de individualización a través de la música conlleva una doble cara; por un lado, implica el afianzamiento de un ejercicio de regulación de los impulsos vinculado a la consolidación de 
mensajes musicalizados, promovidos como grandes enunciados que sirven cual marcos del accionar individual permitido. Como contracara, los instrumentos musicales sirven para realzar el lugar de los cantantes y su performance - no en pocos casos estos (los cantantes) se muestran como modelo de un exceso, de una desregulación que no todos pueden ejercer y que le permiten un lugar especial de presentación y de distinción-. En este sentido, el artista funciona como modelo que potencia, a través de la experiencia sensible que produce en sus seguidores, una referencia para el movimiento de los individuos (Lipovetsky, 1996).

Es en ese transcurrir de lo grupal a lo individual que se apaciguan las tensiones y se exalta la libertad de los sujetos para tomar sus propias determinaciones, se trata de un transcurso en el que se amansan nuestros deseos e impulsos y accedemos a un marco de relaciones reguladas y "libres", mejor entendidas como relaciones "civilizadas" (Elias, 1989). El sentido de lo íntimo o de lo individual no significa la inexistencia de un lazo que lo conecte con lo colectivo; sin embargo, parece existir una tendencia a considerar lo individual como un asunto aislado e impermeable, como absolutamente autónomo frente a la multiplicidad de relaciones que sostienen una ubicación propia en un plano social.

Lo que se busca resaltar aquí es la idea de un entramado de interdependencias que se constituye para que se dé una $\mathrm{u}$ otra forma de colectividad, una u otra forma de singularidad, o si se quiere para que se configure cierta sonoridad, cierto género musical predominante en un momento dado. De forma paralela a tal entramado se encuentra la idea de un individuo autónomo, del artista puro (aquel anclado en la idea del arte por el arte) o de la música absoluta como modelos de una estética superior que innatamente posee los valores de la distinción y que se muestra sin aparentes conexiones socioculturales, cuestión que bien sirve como ejemplo de un fuerte idealismo embriagado en las formas puras.

Puede ayudarnos a aclarar un poco más este asunto introductorio si recordamos algunas ideas que sugiere Norbert Elias:

Cada ser humano particular queda, de hecho, atado; queda atado por cuanto vive en constante interdependencia funcional con otras personas; es un eslabón de la cadena que ata a otras personas, y cada una de esas otras personas es -directa o indirectamente- un eslabón que lo ata a él. Estas cadenas no son tan visibles y palpables como las cadenas de hierro; son más elásticas, variables y alterables, pero no son menos reales y, con toda certeza, tampoco menos firmes (1990, p. 31).

Este entrelazamiento de los individuos puede reconocerse en diferentes periodos históricos; en el tiempo de la sociedad actual existe una concatenación que ecualiza lo colectivo en aras de la afirmación de lo individual, asunto característico de la modernidad y que podemos reconocer como factor influyente en las dinámicas de las creaciones estéticas: "el artista se muestra en su obra". Claro, pero el artista lo es en un marco de interrelaciones, así que bien podría decirse que en las creaciones sonoras, pictóricas, plásticas y de diversas variantes, se encuentran escenificados, en gran medida, los juegos de relaciones de un individuo ligado a otros individuos. 
Así, varios siglos atrás los nobles y cortesanos contemplaban obras musicales en sus propios auditorios o en grandes teatros, mientras el común de la gente hacía uso de los músicos marginales para ambientar sus reuniones. La música sirvió de diferentes modos a pesar de que en la historia musical se perpetuó y difundió una imagen agrandada de su papel como distractora de la élite noble: exaltando a virtuosos compositores o interpretes, imponiendo un velo al universo sonoro plebeyo. Tal vez habría que mirar cómo se constituyó tal orden de relaciones alrededor de la música y sus oyentes, asunto que desborda las pretensiones de este escrito.

Por otra parte, el proceso muy posterior - a mediados de la primera mitad del siglo $X X$ - hacia un nuevo entramado de relaciones posibilitó que se masificara el acceso a los conciertos por medio de la radio y los discos, y los cantantes ganaron una gran centralidad que los llevó a hacer grandes recorridos por diferentes rincones del planeta. Estos dos momentos dejan ver el cambiante lugar de lo musical y llaman la atención sobre la forma como actualmente se configura esta práctica estética. Una mirada sobre el caso de la música reggae podrá ofrecernos algunos detalles sobre el tema: la manera como se establece un orden del sonido, un orden de las posiciones instrumentales y de las posiciones sociales.

\section{II}

La música reggae posee un trasfondo histórico-social rico en matices; vale la pena resaltar que fue el sonido que ambientó e influenció el proceso de independencia de Jamaica hacia finales de los años sesenta del siglo XX. Por tal motivo, se le ha asignado un fuerte valor político y a su vez se le ha vinculado con el movimiento Rastafari de la isla ${ }^{3}$. Sin embargo, como lo plantea Giovannetti (2001), estas características han sido cuestionadas, ya que se ha dicho que el tema político no fue el único asunto que abordó está música y que no deberían desconocerse sus vínculos con el rocksteady, género que hizo fuerte alusión a temas románticos (amorosos) y que fue considerado como cuna del sonido reggae. Igualmente, algunos investigadores han desligado al movimiento Rastafari como eje de tal música y como fuente exclusiva de las líricas (Chang y Chen, 1998).

Es importante subrayar que la sociedad jamaiquina contemporánea está constituida mayoritariamente por afrodescendientes cuyos antepasados fueron esclavizados y quienes tuvieron que vivir una fuerte represión y negación cultural. Los sonidos históricamente predominantes en la isla estuvieron conectados con el sólido desarrollo de un trabajo coral ligado a la religión protestante de los amos, y a la vez desarrollando formas propias africanizadas y caribeñas como la Iglesia de la Revitalización de Sión. A la par y de forma oculta, otras prácticas culturales se sostenían como la Pokomenia y la Kumina, en las "sombras" de una sociedad colonialista. Este marco social impregnó esos sonidos y bailes negados siendo motor de variados ejercicios de resistencia social, dentro de los cuales se encontraban rituales Obeah (hechizos y manejo de lo

3 En términos muy resumidos y generales el rastafarismo tiene sus orígenes en los años treinta del siglo XX: asume a Haile Selassie -emperador de Etiopia - como divinidad; a África, especialmente a Etiopia como Sion, la tierra prometida, y a Jamaica como Babilonia, la tierra de perdición; y al pueblo afro-jamaiquino como reencarnación del pueblo de Israel esclavizado en Egipto. 
sobrenatural), narraciones de Anansi o juegos musicales de percusión africana (Bastide, 1969; Giovannetti, 2001; Friedemann y Arocha, 1986) $)^{4}$.

Toda esa tradición en la que se empapaba el transcurrir sociocultural jamaiquino fue constituyendo el empuje, el dinamismo relajado, las discrepancias sonoras desde las que floreció la música reggae y desde las que se influenció a toda la región insular caribeña. La idea de discrepancia se sintoniza con lo sugerido por Charles Keil (2001) acerca de las discrepancias participatorias en las que se conjugan sentidos de ritmo, impulso vital o swing con cualidades del tono, timbres, entre otros. Así mismo, se sostiene que "para poder producir una implicación personal y ser socialmente valiosa, la música ha de ir 'a destiempo' y estar 'desafinada'” (Keil, 2001, p. 261). De tal modo, la música en el contexto jamaiquino y en gran parte del Caribe insular postcolonial habilitó la "participación relajada" de la comunidad en el ejercicio de la afirmación de un sentido de identidad grupal más allá del tempo marcado por el establecimiento (neo)colonial.

El empuje, el sabor, el irie o skank $k^{5}$ musical sintetiza en gran medida ese ejercicio de armonización colectiva que se mueve a des-

4 El caso de las Anansi Stories es muy importante en el contexto de la historia oral de las comunidades afroamericanas; Anansi es, en la lengua akan de los Ashanti-Fanti africanos - que ocupan actualmente parte del territorio sur de Ghana - una palabra que significa araña. En la isla de San Andrés esta palabra hace referencia a una serie de historias (dichos, chistes, cuentos), mantenidas a través de la tradición oral, en las que se presentan subversiones frente a la realidad imperante. Las historias de la araña sugieren una inversión del orden de las posiciones, allí un animal pequeño y aparentemente débil nos enseña el poder de la astucia y la inteligencia para vencer al más fuerte (Pochet, 2008).

5 Aunque puede ocurrir que el termino skank sea usado habitualmente para hacer referencia al estilo sincopado y el ambiente que produce la música reggae, se ha hecho referencia en este caso al irie como tiempo del ritmo dominante y que propone en su transcurso otro orden de relaciones. El irie en la música reggae puede entenderse como un encontrarse en el "nivel", en el punto óptimo, en el poder adecuado que genera movimiento. Esta palabra del patois jamaiquino hace parte del lyaric, del dialecto de la resistencia afrocaribe configurada en medio de un contexto anglófono (Pollard, 2000). Lyaric es el lenguaje, la desafinación y el destiempo colectivo que se evidencia y se recrea en el irie del grupo de música reggae; en este sentido, el grupo musical sirve como una representación a escala de ese sentido social discrepante. La discrepancia consiste en un ejercicio de resistencia hecho música, activado en los juegos rítmicos, melódicos y en los discursos que proponen (que se oponen, en el caso jamaiquino y a través de su proceso histórico, a la versión musical del amo, del colono, del "blanco", como parte de una lucha histórica por la reconfiguración de poderes y sentidos grupales).

En San Andrés Isla, territorio colombiano con pasado colonial ligado a Inglaterra, ubicada a $772 \mathrm{~km}$ de las costas nacionales y a 643 $\mathrm{km}$ de Jamaica, el irie del reggae se vive de un modo propio $^{6}$. Allí, por la influencia de sonidos y géneros populares como la soca, el vallenato, el reggaetón o la salsa, existe una matización, unas nuevas discrepancias conjugadas. Debido a la constante prohibición de los tambores (por la relación que el amo inglés reconoció entre la producción de su sonido y la organización de rebeliones) ejercida durante diferentes momentos de

palabra continuamente mencionada por músicos de San Andrés y en diversas canciones en tiempos recientes.

6 En el siguiente enlace puede consultarse la ubicación precisa de la isla (muy cercana a Nicaragua): http://geoportal.igac.gov.co/mapas_de_colombia//GAC/Tematicos2012/FronterasMaritimas.pdf. 
la colonización isleña, es fácil encontrar los rastros de tal herencia en el presente; buena parte de las bandas se sostienen en la mezcla de sonidos de los géneros del calypso y del reggae, con un formato que incluye la guitarra, la mandolina, las maracas, la quijada de burro y la tinaja, evitando el uso de tambores (Bermúdez, 1998) ${ }^{7}$.

Si se tuviese que hablar de una fuerza predomínate en tiempos recientes, jalonadora del ritmo musical y social en San Andrés, puede aludirse a un fuerte acompasamiento en términos de dinámicas de exotización y promoción turística del Caribe iniciada por el Estado colombiano desde mediados del siglo XX. Sin embargo, entre bastidores de la actividad comercial se sostienen ejercicios musicales que propenden a la constitución de otras voces, y configuran así gramáticas culturales alternas y a contratiempo (Pochet, 2008; Sánchez, 2007).

Puede hablarse en términos generales de un "modelo" rítmico desde el cual se estructuran las canciones de música reggae, que consiste básicamente en la unión de compases de 4/4 atresillados (con diversas variantes de tresillos de corchea), en los que se acentúan los tiempos 2 y 4 continuamente -en especial por la guitarra o los teclados-y se acompaña por una rica línea del bajo que evita el tiempo 1. En el cruce de juegos de acordes unidos con las líneas del bajo y una base de batería que podría considerarse muy similar a la del rock - pero que da en el sonido seco y grave del bombo lo que en el rock es el golpe de caja (con usos especiales del hi-hat y acentuaciones en los aros del

7 Un ejemplo del formato instrumental convencional en la ejecución de calypso o el reggae isleño puede verse en el siguiente link del grupo Coral Group: http://www.youtube.com/watch?v=6JdnZZ8WnPs. redoblante, entre otras variaciones)—, se va urdiendo una cadencia roots.

Esta cadencia remite al oleaje de la memoria, al juego y corrimiento que culturalmente ejerce la comunidad y que es sintetizado por sus músicos frente a las marcas rítmico-sociales establecidas (recordemos que la música reggae está ligada a la expansión de la música jazz, ambos géneros sonoros nacen con una carga de marginalidad y sentimiento grupal similar). En este contexto cadencial se rehace y resignifica el presente; allí la comunidad se reposiciona en medio de un vaivén social atravesado por sufrimientos, raíces africanas en ampliación, persistencias, luchas de sentido que escapan a un orden fijo del movimiento (Kwesi Johnson, 1974).

Igualmente, en la repetición de la estructura sonora se recrean continuamente las líricas y se sostienen perspectivas de percepción desde las que se intenta resistir la pesada fuerza comercializadora ejercida sobre el sonido (fuerza ligada a la producción y masificación de éxitos musicales). El carácter contestatario del reggae remite a una geocultura de las emociones que le atraviesa históricamente, en esta línea la rememoración del dolor grupal funciona como potencia para la creatividad y la orientación social.

En el caso del reggae jamaiquino pueden encontrarse evidencias de este "dolor social" en múltiples letras de canciones populares, por ejemplo en Slavery Days de Burning Spear, 400 Years de Peter Tosh o Lift Up Your Conscience de Israel Vibration. En la isla de San Andrés ocurre algo similar, no son pocas las canciones que aluden a un dolor común: Up Side Down de The Rebels, Who Can Live There de Sister Celis o Pañaman de 
Félix Mitchell Gordon testimonian tal sentir ${ }^{8}$. Así mismo, músicos como Joselin Wilson aseguraron que "no debemos olvidar que siempre nos han tratado como si no tuviéramos valor, la gente que ha gobernado desde hace siglos nos ha hecho sufrir, mis padres me contaban que eso siempre fue igual"; Ángela Steele agregó, "en medio de una historia de siglos de dolor la música nos orientó y seguimos luchando".

De tal forma, a pesar de la gran influencia de los circuitos sonoros ligados al turismo, se han sostenido espacios desde los cuales se le apuesta a una dimensión política del sonido. Tal dimensión es construida a partir de la socialización cotidiana, fortalecida a través de la memoria colectiva, evidenciada en los mensajes musicales y reafirmada en comunidad - en el baile- - En todo caso, sería atrevido sostener que el actual énfasis temático del reggae sea puramente político. En cambio, sí podemos indicar que la conformación rítmica sociomusical en la vida isleña sanandresana remite a:

[...] una forma de conciencia que se manifiesta en el conocimiento práctico, esto es, un "ser capaz de" — practognosis, en términos fenomenológicos de Merleau-Ponty - por medio del cual las distinciones se establecen alrededor de "quienes saben" (quienes son capaces de) cómo ejecutar y [sobre todo] bailar [reggae], y aquellos "quienes no saben" (Ferreira, 2007, s. p.) (la negrita es mía $)^{9}$.

8 Una compilación de canciones raizales, en la que están incluidas aquellas que se mencionan en este escrito, puede escucharse en: http://www.youtube.com/user/CaribbeanSongs.

9 La version en ingles en el texto de Ferreira dice así: "A form of consciousness is manifested as a practical knowledge, that is, "being able to" - praktognosis, in Merleau Ponty's phenomenological terms_-by
Esta distinción del saber o no saber es muy importante cuando se tienen en cuenta preceptos morales, ethos sociales (sentidos políticos) de la comunidad raizal a partir de los cuales ella se orienta hacia aquellos aspectos-acciones que facilitan una mayor cohesión y perspectiva colectiva. Este "saber hacer" esta sintonizado con una historia propia hecha cuerpo: tradiciones orales, danzas, alimentos (platillos), costumbres y musicalidades (Dittman y Pomare, 2000).

En esta dirección, el irie musical indicaría un saber incorporado que, a modo de ejemplo y de forma muy específica, a través de la guitarra va marcando los acentos e intensidades para recrear una tradición propia, jugando con el silencio y exaltando sus voces. Recordemos que este tipo de guitarra reggae adquiere uno de sus elementos de conformación desde el ámbito de la iglesia protestante, dentro de un contexto social y musical "a tempo", y que en el juego de subversiones entramado en la cotidianidad isleña adquiere su sentido sincopado. Esta síncopa de la guitarra se sintoniza con las flexiones continuas de las rodillas en el momento del baile, en claro contraste frente al baile disciplinado que ya había enseñado el amo blanco siglos atrás. En gran medida se trata de reconfiguraciones sonoras en las

means of which distinctions are made among those 'who know' (who are able to) how to play and dance candombe, and those 'who do not'". Aclaramos que el trabajo de Ferreira corresponde a una observación sobre los tambores del candombe en el contexto uruguayo, asunto que no pretendemos equiparar con nuestras observaciones sobre San Andrés. Más bien buscamos resaltar el carácter fenomenológico de aspectos sociomusicales - de los modos de una "conciencia grupal práctica y pre-predicativa"- que caracterizan a los raizales sanandresanos, a partir de los cuales ellos pueden modular variantes de un ejercicio de diferenciación social respecto a los visitantes o nuevos pobladores. En este sentido, bailar reggae (o calypso, y si es el caso, tocar tales músicas) es un aspecto clave que los inscriben en una tradición afrobritánica distante de la cultura hispánica que las instituciones gubernamentales han intentado imponer. 
que también se animan las tácticas populares, y se han abierto históricamente otras relaciones de conocimiento ${ }^{10}$.

Si los sonidos organizados socialmente modulan "categorías particulares de sentimiento y acción" (Feld, 2001, p. 332), entonces, por ejemplo, saber crear un ambiente con la guitarra no consiste en un puro saber individual, sino que es a través de esa guitarra y la forma sincopada del rasgueo que se amplifican una historia social, unas formas de sentir y de actuar como grupo. Frecuentemente los músicos, especialmente algunos guitarristas raizales que consultamos, afirmaron que el reggae no tuvo ni ha tenido un lugar especial en el mercado sonoro debido a su ligazón con una tradición de marginales y reprimidos, música de aquellos a quienes no se les ha permitido la libertad del "decir" (esto no significa que comercialmente no se haya explotado el carácter marginal como elemento pintoresco y atrayente). Entonces al construir su voz, su estilo de tocar la guitarra, intentan sostener una memoria de la historia de sus padecimientos y penas; motor de su musicalidad, asunto que los artistas representativos de este género constatan ${ }^{11}$.

Bob Marley comenta en una entrevista, cuando le preguntan si la música reggae puede ser copiada fuera de Jamaica (a lo que podríamos agregar "fuera del Caribe británico afroinsular"), que "Well, if you see

10 Un ejemplo del movimiento corporal básico en el baile reggae puede verse aquí: https://www.youtube.com/watch?v=NyPfD6zOAAc

11 Un músico en la playa comentó que "ser rasta vende para el turista, si digo que soy de la familia de Tosh algo sale, pero si hago mis canciones más difícil será [...] con otro público más de aquí, ellos tal vez aceptan más mi música, entienden más porque hablo de lo que nos pasa y de nuestras historias, pero difícil será que mi música se venda". way I feel about the music, it [reggae] can be coppied, you know? [...] But, it's not copy do it. It's the feel, you know? It carry a feel. Well, if you ask plenty musician them know it but them can't do it"12. La particularidad del sonido reggae caribeño insular afrobritánico se inscribe en una historia social del sentir de la cual la sociedad raizal de San Andrés hace parte, y tal sensibilidad que puede entenderse como una especie de segunda naturaleza va más allá de la repetición de una estructura rítmico-armónica que los músicos pueden apropiar técnicamente.

Ello no significa que se abogue por la existencia de una "sensibilidad caribeña innata" que se corresponde con una forma de musicalidad determinada; más bien se intenta resaltar la relación que se da entre musicalidades y prácticas sociales como fuentes de un(os) ritmo(s) social(es) en proceso. Con esto puede insistirse acerca de nuestra idea del ejercicio musical individual modelado e inscrito en (ligado necesariamente a) un entramado de interdependencias y enmarcado en el "curso" de procesos sensibles histórico-sociales.

Linton Kwesi Johnson agrega que (desde un contexto afroinsular caribeño):

[...] [i]t is a music that is at once violent and awesome, forceful and mighty, aggressive and cathartic. It is a music that beats heavily against the walls of babylon, that the walls may come a-tumbling down; a music that chucks an heavy historical load that is pain that is hunger that is bitter that is blood, that is dread (Kwesi Johnson, 1976, p. 397).

12 La entrevista realizada por Dylan Taite a Bob Marley en Nueva Zelanda, en 1979, puede verse a través del siguiente enlace: http:/l www.youtube.com/watch?v=tkhRVdcnDZY 
En esta línea, la crítica de Steven Feld es oportuna para el caso de San Andrés; él cuestiona muchas investigaciones cuyo axioma ha sido que "cuando el sonido no es complejo en los aspectos materiales de su organización acústica, puede asumirse que su significado social será esencialmente superficial" (Feld, 2001, p. 332). En el caso del reggae sanandresano la simplicidad de su estructura puede ser a su vez la fuente de creación de sentidos y resistencias, un espacio donde se resguardan y potencian perspectivas de colectividad.

\section{III}

Los grupos de música reggae en San Andrés poseen un formato instrumental similar al del rock: bajo, batería, guitarra, coros y voz principal; claro, en varias ocasiones se incluyen teclados e instrumentos más cercanos al calypso, como la quijada de burro, la tinaja, la mandolina o el violín. Aunque no es fácil integrarse a los grupos locales siendo foráneo, pues existen prevenciones y prejuicios frente a los visitantes continentales, es posible construir un camino de acercamiento a partir del reconocimiento de la historia de la isla. De acuerdo con mi experiencia, cuando los músicos isleños se dan cuenta de que los vínculos con el visitante se salen del esquema del consumo turístico se sienten extrañados y curiosos.

Igualmente, cuando las personas sienten un apasionamiento común por lo musical, un interés de descubrimiento y práctica, entonces se suavizan las murallas sociales y el fluir sonoro empapa la interrelación (Benzecry, 2012). El conocimiento e interés por el reggae incluye en este caso, en la vida de la isla, una atracción hacia el baile: "se toca, se escucha y se baila", es ahí donde la practognosis es protagónica. Es también ahí donde las formas culturales se tensionan, pues existen "modos de ser" colombianos asignados para el caribeño o el andino ${ }^{13}$, asignaciones sociales que pesan en el sostenimiento de diferenciaciones y posicionamientos sociales. Al intentar salir de tales marcos se habilita un corrimiento de los límites y el intercambio musical fluye por nuevos caminos.

Esta dinámica de encuentro, aproximación, vinculación y reconocimiento dirigido a la música, a los patrones sónicos, es también un vivenciar el ethos social y emocional de la comunidad (Feld, 2001). Se descubre entonces que, en San Andrés "[1]os principios [musicales] son corporizados [específicamente en la danza] y transmitidos por la práctica y la performance misma, de una generación a otra, aprendidos en comunidad pero no enseñados, como una dimensión de resistencia étnica" (Ferreira, 2007 , s. p. $)^{14}$. Este aprendizaje está constituido por juegos vocales que a los niños les inculcan los abuelos en la casa o en el barrio (practica que se ha ido debilitando en consonancia con los procesos de temprana escolarización), por espacios radiales que difunden música reggae y por las fiestas (en barrios y en bares, divididas o mezcladas

13 Es necesario tener en cuenta que en Colombia existe una diferenciación muy fuerte entre lo que es ser costeño (caribeño) y lo que es ser cachaco (término usado habitualmente para referirse a los bogotanos que visitan otras zonas del país, aunque igualmente es usado en la costa Caribe para designar a todos aquellos que viven al interior del país más en cercanía con la cordillera). Con estos dos términos se ponen en juego posicionamientos de clase y mecanismos de valoración/estigmatización social.

14 La versión original en inglés dice asi:: "These principles are embodied and transmitted by the practice of performance itself, from one generation to another, learned in community but not teached, as an ethnical resistance dimension". 
generacionalmente) en las que también se escucha música calypso, soca, dancehall, reggaetón, vallenato y salsa.

Doblar las rodillas (danzar) siguiendo el irie de la guitarra, el continuo rasgueo seco que se mantiene a destiempo, constituye una experiencia que implica todo el compromiso personal-social de sostener la base, de sostener el lugar desde el cual músicos y bailarines realizarán la improvisación. Esta última consiste básicamente en el juego que crea la banda a través del cantante, quien va orientando al público para que sostenga un coro que le servirá como piso para introducir sus versos. A diferencia de las presentaciones que lo músicos raizales ofrecen a los turistas, en las que se define un repertorio con canciones enmarcadas en la "hora del show isleño" (que muchas veces invitan al baile grupal guiado por un bailarín local que define las coreografías), la experiencia de la comunidad (de aquellos que participan y coinciden en su gusto por el reggae) habilita un diálogo sonoro en el cual la banda propone una estructura musical que el cantante complementa incentivando la participación de los oyentes-cantantes-bailarines.

Aunque las canciones pueden tener una letra y una duración ya definidas, la ampliación de las mismas se da en medio de la sintonización que se logra desde la puesta en circulación de lo que nosotros percibimos como un oleaje sonoro-emotivo, un vaivén (más allá de una mirada simplemente romántica), del sentirse afectado y sostenerse unido al otro, de un ambiente que estimula al movimiento colectivo desde el movimiento de los músicos ejecutando los temas (y viceversa), y que hace partícipe a las personas en la construcción de la atmosfera. Así, fácilmente puede escucharse un coro repetido por el público que dice: ।-- -- -- -Wolyo o o -wolyoyo yo yo -- I, que en la reiteración va creando una impresión compartida por todos los performers, de ir y venir, propiciando una sensación común de estar navegando con mucha calma ${ }^{15}$. Todo desde el sostenimiento sólido del irie, de la cohesión de la base como constatación de la vivencia personal del mundo circundante: del aire, la playa, el agua, de las dificultades socioeconómicas comunes, del sonido y el movimiento corporal, del movimiento de la mano y el rasgueo "(im)preciso", milimétrico que se conjuga con los demás instrumentos y con el baile y las voces de las personas.

Aunque la organización de las posiciones de los músicos en el escenario es similar a la del rock (batería en el fondo, bajo y guitarra a los costados, cantante en el centro), el interés por la incorporación de los oyentes coincide con la reproducción del formato del canto responsorial religioso. Canto que intenta fundir en uno solo tanto el lugar del músico, como el de la 'audiencia', con miras a fortalecer la virtud común más que enaltecer un ámbito puramente artístico o simplemente individual. Así, por ejemplo, la insistencia sobre la idea de resistir colectivamente a Babylon es recurrente y es un tema central desde el cual se modelan buena parte de las canciones. Babylon es todo aquello que corrompe la unidad grupal, todo aquello que silencia las voces de la tradición y es

15 En no pocas oportunidades, músicos y espectadores coincidieron en la metáfora del "mar" para hablar de la música reggae. Luis O’Neill, guitarrista de la agrupación The Rebels, sugirió que "esta música es como las olas que vienen y van, en medio de la lucha del día a día, con su fuerza y tibieza no te dan ganas de salir de ellas [...]"; Teresa Abrahams, cantante del coro católico, afirmó que "el reggae es como este mar y este paisaje..., tan tranquilo..., a veces tormentoso..., y produce reflexiones, encuentros que no debemos olvidar". 
también el sistema occidental de jerarquización, explotación social y económica.

El ethos puesto en juego en la práctica musical entonces aparece con doble cara; por un lado, como presentación exigida en el marco del circuito turístico-comercial; por otro lado, como espacio de cohesión y fortalecimiento grupal desde el cual se promueven miradas y sentidos de vida. Una cara es expuesta estratégicamente cual disfraz emocional, con unos repertorios establecidos frente al público que consume lo "típico de la isla exótica". Otra cara es reservada para las estrategias y tácticas de la resistencia. En medio de las tensiones que tal situación implica, preguntarse por los equilibrios puestos en juego entre las acciones individuales y las acciones colectivas lleva a reconocer el peso fuerte de lo grupal, entendido como ethos, en la afirmación de la acción personal.

Consideramos que en la configuración de musicalidades se rehace la experiencia histórico-grupal que se tiene del entorno; es a través de múltiples percepciones que se da la aproximación al instrumento, y en el contacto con los otros se entretejen modos del sentir. La música promueve entonces sentidos afectivos que crean un campo de relación y de acción, que en el proceso de hacerse cuerpo se dejan ver (tales sentidos) como un orden moral. Este orden sintetiza un proceso sociohistórico que en el caso sanandresano permite reconocer un contrapunto, unas síncopas sociales respecto a una tendencia puramente centrada en lo individual o alineada con el puro disfrute de hits musicales y la reproducción del modelo sensible que estos proponen ${ }^{16}$.

16 Con estas ideas no se busca sostener que cualquier baile 0 canto grupal implique necesariamente una forma de resistencia social,
El ethos no individualista en la práctica de este género jamaiquino en la isla de San Andrés evidencia formas de construcción cultural que son potencias sonoras jalonadoras de otros equilibrios de relación. En nuestra observación, descubrimos el espacio del canto colectivo local, de la danza compartida y de la práctica musical como ligazón social, una fuente que se opone al dominio imperante del comercio sonoro y su énfasis individualizador (cual anestesia-consumista). Aunque la revisión del vocabulario emocional presente en las canciones más populares en San Andrés permitió ver una tendencia temática centrada en la pareja y el enamoramiento —como parte de una dinámica de educación sentimental y del establecimiento de modos corporales funcionales para la validación de las jerarquías sociales-, no se puede negar la existencia de letras musicales populares como Hard Time, True Born Islander, Spade o Jail Them, entre otras, en las que los compositores raizales denuncian las dificultades que vive su sociedad y alientan el mantenimiento y promoción de su colectividad.

En esta oportunidad se ha intentado describir y problematizar mí experiencia musical en San Andrés como abrebocas para una profundización posterior de las ideas que son sugeridas en el escrito. Algunas de las dudas que surgen en el recorrido son las siguientes: ¿qué grados de autonomía tienen los músicos de reggae en San Andrés en otros contextos sonoros y cuáles son sus relaciones con el grupo al cual pertenecen y se dirigen? ¿Qué sensibilidades son activadas de acuerdo con cada género musical y

más bien se resalta el contexto, los mensajes y las perspectivas que se activan colectivamente para fortalecer proyecciones y pautas de acción común. 
cuáles son sus incidencias en el tejido de las relaciones sociales? ¿Qué mensajes, prácticas y modelos son promocionados en las músicas más populares del planeta y cómo van estructurando un orden moral colectivo planetario? Estas son algunas de las inquietudes que sirven como cierre en este ejercicio de reflexión y que reconocen una fuente de poder y modelación social a través de los fenómenos musicales.

\section{REFERENCIAS}

Bastide, R. (1969 [1967]). Las Américas Negras. Las Civilizaciones Africanas en el Nuevo Mundo. Madrid: Alianza.

Benítez Rojo, A. (1997). Significación del ritmo en la estética caribeña. En J. Becerra (Coord.), Caribe 2000: definiciones, identidades y culturas regionales $y$ nacionales (pp. 84-97). San Juan: Universidad de Puerto Rico.

Benzecry, C. (2012). El fanático de la ópera. Buenos Aires: Siglo XXI.

Bermúdez, E. (1998). La tradición musical religiosa de las comunidades afroamericanas de habla inglesa: el caso de San Andrés y Providencia, sus iglesias y su música. En A. Saldarriaga (Comp.). Las iglesias de madera de San Andrés y Providencia. Bogotá: Fundación DE MVSICA.

Bermúdez, E. (2003). Las músicas afrocolombianas en la construcción de la nación: una visión histórica. VI Cátedra Anual de Historia Ernesto Restrepo Tirado (Comp.), 150 Años de la abolición de la esclavización en Colombia (pp. 706-725). Bogotá: Aguilar.

Borde, P. (1973). The sounds of Trinidad: the development of the steel-drum bands". The Black Perspective in Music, 1(1), 45-49.
Brueghel, P. y Bianconi, P. (1988). La obra pictórica de Brueghel. Madrid: Planeta.

Calvancanti, C. (1985). Rastafari: los caminos autónomos hacia la identidad. En $E l$ Caribe Contemporáneo, (10), 123-128.

Carvalho, J. (1995). Hacia una etnografía de la sensibilidad musical contemporánea. Brasilia: Serie Antropología 186.

Chang, K. y Chen, W. (1998). Reggae routes: the story of jamaican music. Kingston: Ian Randle Publishers.

Clemente, I. (Coord.) (1989). San Andrés y Providencia: tradiciones culturales $y$ coyuntura política. Bogotá: Ediciones Uniandes.

De Vrij, M. (2006). Jan Mandyn. Toronto: M.R.V. Publishers.

Dittman, M. y Pomare, L. (2000). Nacimiento, vida y muerte de un sanandresano. Bogotá: Ministerio de Cultura.

Edström, O. (2012). Elias and/or Adorno - a short personal reflection and perspective from a musicologist. Human Figurations Journal, 1(1), 1-14.

Elias, N. (1989 [1939]). El Proceso de la Civilización. México, D. F.: Fondo de Cultura Económica.

Elias, N. (1990 [1987]). La Sociedad de los Individuos. Barcelona: Península.

Elias, N. (1991). Mozart: sociología de un genio. Barcelona: Península.

Feld, S. (1982). Sound and sentiment: Birds, weeping, poetics and song in Kaluli Expression. Philadelphia: University of Pennsylvania Press.

Feld, S. (2001). El sonido como sistema simbólico. En F. Cruces (Coord.), Las culturas musicales. Lecturas de etnomusicología (pp. 331-356). Madrid: Trotta.

Ferreira, L. (2007). An afrocentric approach to musical performance in the black south Atlantic: the candombe drumming 
in Uruguay. Recuperado el 23 de abril de 2013, de http://www.sibetrans.com/ trans/

Friedemann, N. y Arocha, J. (1986). De sol a sol. Génesis, transformación y presencia de los negros en Colombia. Bogotá: Planeta.

Giovannetti, J. (2001). Sonidos de Condena. México, D. F.: Siglo XXI.

Grosso, J. L. (2009). Cuerpos del discurso y discurso de los cuerpos. Nietzsche y Bajtin en nuestras relaciones interculturales. Revista Latinoamericana de Estudios sobre Cuerpos, Emociones y Sociedad, (1), 44-77.

Houk, J. (1995). Spirits, blood and drums: the Orisha religion in Trinidad. Philadelphia: Temple University Press.

Keil, C. (2001). Las discrepancias participatorias. En F. Cruces (Coord.), Las culturas musicales. Lecturas de etnomusicología (pp. 261-274). Madrid: Trotta.

Kwesi Johnson, L. (1976). Jamaican rebel music". Race E Class, (17), 397-412.

Lipovetsky, G.(1996). La era del vacío. Ensayos sobre el individualismo contemporáneo. Barcelona: Anagrama.

Madrid, A. (2008). Nor-Tec Rifa! Electronic cance music from Tijuana to the world. Oxford: Oxford University Press.

Magallanes, G. et al. (2014). Expresividad, creatividad y disfrute. Buenos Aires: Estudios Sociológicos.

Parsons, J. (1985). San Andrés y Providencia, una geografía histórica de las islas. Bogotá: El Áncora.
Pochet Rodríguez, L. (2008). Las telas transgresoras de la Araña Anancy en el Archipiélago de San Andrés, Vieja Providencia y Santa Catalina (Colombia) y en la Provincia Atlántica de Limón (Costa Rica) (Tesis de doctorado). Universidad de Ámsterdam, Ámsterdam.

Pollard, V. (2000). Dread talk. The language of rastafari. Kingston: Canoe Press.

Rao, A. y Sedlaczek, Y. (2012). Calypso in the Caribbean: a musical metaphor for Barbados. International Journal of Cross Cultural Management, 12(3), 315-327.

Restrepo, L. A. y Ramírez, S. (Eds.) (2001). Cuadernos del Caribe № 1 . Visiones y proyectos para el Archipiélago de San Andrés, Providencia y Santa Catalina. San Andrés: Universidad Nacional de Colombia.

Sánchez Aguirre, R. (2007). Marginados o establecidos: identidad Sanandresana, proceso social 1970-1991 (Tesis de maestría). Universidad Javeriana, Bogotá.

Sánchez Aguirre, R. (2014). Emociones y música: sociología de las regulaciones emotivas a través de las canciones de la isla de San Andrés (Tesis de doctorado). Universidad de Buenos Aires, Buenos Aires.

Scribano, A. (2012). Sociología de los cuerpos/emociones. Revista Latinoamericana de Estudios sobre Cuerpos, Emociones y Sociedad, (10), 93-113.

Simmel, G. (2003 [1882]). Estudios psicológicos y etnológicos sobre música. Buenos Aires: Gorla. 